\title{
Frontline treatment patterns and attrition rates by subsequent lines of therapy in patients with newly diagnosed multiple myeloma
}

Rafael Fonseca ${ }^{1 *}$, Saad Z. Usmani², Maneesha Mehra ${ }^{3}$, Mary Slavcev ${ }^{3}$, Jianming He ${ }^{3}$, Sarah Cote ${ }^{3}$, Annette Lam³ Jon Ukropec ${ }^{4}$, Eric M. Maiese ${ }^{5}$, Sandhya Nair ${ }^{6}$, Ravi Potluri ${ }^{7}$ and Peter M. Voorhees ${ }^{2}$

\begin{abstract}
Background: For patients with multiple myeloma (MM), each additional line of therapy (LOT) is associated with lower response rates, shorter treatment duration and treatment-free intervals, and increased rates of toxicities and comorbidities. Here, we examine frontline treatment patterns, and attrition rates by LOT among newly diagnosed MM (NDMM) patients in the United States who were eligible or ineligible for autologous stem cell transplant (ASCT).

Methods: Data were identified from three US patient-level databases collectively covering the period January 2000 to September 2018. Patients had an index diagnosis of MM on or after January 1,2007, medical and prescription insurance coverage at diagnosis, a 1-year look-back period prior to the index diagnosis, no prior malignancies in the 1year period before index diagnosis, and had received $\geq 1$ LOT.

Results: Among patients who did not receive ASCT (non-transplant; $n=22,062), 12,557$ (57\%) received only 1 LOT and 9505 (43\%) received > 1 LOT. Patients receiving only 1 LOT were significantly older, had higher mean Charlson Comorbidity Index (CCl) scores, and higher incidences of comorbidities. Among the 2763 patients receiving ASCT, 2184 received > 1 LOT, and 579 (21\%) received only 1 LOT (ie, ASCT was the last treatment). 1682 (61\%) patients received induction therapy as frontline treatment, of whom $187(11 \%)$ also received consolidation therapy. The latter group was younger than those who received only induction therapy, had lower mean CCl scores, and comparable or lower incidences of selected comorbidities. The most common frontline therapy for non-transplant and transplant-eligible patients was bortezomib/dexamethasone and bortezomib/lenalidomide/dexamethasone, respectively. Attrition rates across all LOTs were high for non-transplant patients (range, 43-57\%) and transplant patients (range, 21-37\%). Treatment duration decreased by LOT for non-transplant patients and was consistent across LOTs for transplant patients.
\end{abstract}

Conclusions: In this analysis, a substantial proportion of patients with NDMM who received frontline therapy did not appear to receive a subsequent LOT. These high attrition rates underscore the need to use the most optimal treatment regimens upfront rather than reserving them for later LOTs in which the clinical benefit may decrease.

Keywords: Attrition rates, Autologous stem cell transplant, Bortezomib, Dexamethasone, Lenalidomide, Line of therapy, Newly diagnosed multiple myeloma, Treatment duration

\footnotetext{
* Correspondence: fonseca.rafael@mayo.edu

'Division of Hematology and Oncology, Mayo Clinic, 13400 E. Shea Blvd.,

MCCRB 3-001, Phoenix, AZ 85259, USA

Full list of author information is available at the end of the article
}

\section{$\triangle B M C$}

(c) The Author(s). 2020 Open Access This article is licensed under a Creative Commons Attribution 4.0 International License, which permits use, sharing, adaptation, distribution and reproduction in any medium or format, as long as you give appropriate credit to the original author(s) and the source, provide a link to the Creative Commons licence, and indicate if changes were made. The images or other third party material in this article are included in the article's Creative Commons licence, unless indicated otherwise in a credit line to the material. If material is not included in the article's Creative Commons licence and your intended use is not permitted by statutory regulation or exceeds the permitted use, you will need to obtain permission directly from the copyright holder. To view a copy of this licence, visit http://creativecommons.org/licenses/by/4.0/. The Creative Commons Public Domain Dedication waiver (http://creativecommons.org/publicdomain/zero/1.0/) applies to the data made available in this article, unless otherwise stated in a credit line to the data. 


\section{Background}

Multiple myeloma (MM) treatment options have improved in recent years, but MM remains an incurable disease with an estimated 5-year survival rate of 52\% in the United States [1]. Frontline and subsequent treatment options are selected based on a patient's age, frailty, comorbidity status, intolerance, resistance, and/or exposure to previous therapy, and disease biology [2, 3]. If a patient is eligible, autologous stem cell transplant (ASCT) is recommended [2, 3]. Although patients who receive a stem cell transplant and maintenance therapy have superior outcomes compared with those who are transplant ineligible $[4,5]$, both groups of patients frequently experience disease relapse and require subsequent lines of therapy (LOTs).

Clinical trials evaluate the efficacy and safety of a therapy at a given disease stage and can be highly selective for a patient population (ie, by restricting enrollment to patients with good performance status). Although clinical trials provide valuable information for specific therapeutic regimens, there is limited information on the factors guiding treatment patterns and patient outcomes in a real-world setting.

Available real-world data suggest that most patients diagnosed with MM receive frontline therapy (64-95\%); however, attrition rates increase with each successive LOT, with an estimated $32-61 \%$ and $14-38 \%$ of diagnosed patients receiving second- and third-line therapy, respectively [6-8]. The depth of response, time to progression, and duration of treatment decrease with each successive LOT, while the incidences of toxicity increase [6]. Moreover, patient-reported health-related quality of life significantly decreases with each LOT [9]. Together, these data strongly support the use of the most effective therapy upfront.

The impact of newer agents on observed attrition rates has not yet been evaluated. This study utilized the most recent patient-level data available from three databases in the United States, capturing the years 2000 to 2018. Additionally, it characterized and compared newly diagnosed MM (NDMM) patients who did receive ASCT with those who did not by the number of subsequent LOTs received.

\section{Methods}

\section{Data sources}

Patients with NDMM were identified from 3 US databases: the OPTUM ${ }^{\mathrm{TM}}$ Commercial Claims database from January 2000-September 2018, the OPTUM ${ }^{\mathrm{mm}}$ Electronic Medical Records (EMR) database from January 2000September 2018, and the Surveillance, Epidemiology, and End Results (SEER)-Medicare Linked database from January 2007-December 2016. The small number of patients who overlapped between the 2 OPTUM $^{\text {тм }}$ databases were excluded; Medicare Advantage patients were excluded from the SEER-Medicare database. Patientlevel data were included in the assessment if the patient had their first MM diagnosis (defined as their index diagnosis) on or after January 1, 2007, known gender, medical and prescription insurance coverage in place at diagnosis, no previous malignancies in the 1 -year period prior to index diagnosis, a 1-year look-back period prior to index diagnosis, and received $\geq 1$ LOT. Non-transplant patients did not receive ASCT at any time during follow-up. For the SEER-Medicare and OPTUM ${ }^{\mathrm{Tm}}$ commercial claims databases, insurance eligibility information was available, and a patient's follow-up was considered to end when they no longer had continuous eligibility. For the OPTUM ${ }^{\text {тм }}$ EMR data, follow-up ended on the last date of observed activity for the patient.

\section{Measures}

An LOT was identified based on an initial administration of $\geq 1$ anti-myeloma agent that continued until $\geq 1$ agent was discontinued for $\geq 60$ days or until a new agent was administered. The additional rules that were applied to create these LOTs are included in Additional file 1. For transplant patients, consolidation therapy was defined as ongoing treatment (occurring within 4 months of ASCT) for $\geq 1$ month after ASCT, and was the same regimen that was used for induction therapy or was a new regimen that included the induction therapy. Attrition rate was defined as the ratio of patients who did not have record of a subsequent MM LOT because of death or loss to follow-up (ie, no subsequent treatment in follow-up) in the database for any reason. Comorbidities that were considered clinically relevant, the Charlson Comorbidity Index score [10], age at index diagnosis, frontline treatment regimens (eg, bortezomib/dexamethasone $[\mathrm{Vd}])$, and attrition rates at each subsequent LOT up to LOT5 were characterized. Comorbid conditions were evaluated with the use of CCI score. Comorbidities were stratified by age in the non-transplant and transplant patients. Duration of treatment (defined as the number of months from the start to the end of a given LOT) was evaluated at each subsequent LOT.

\section{Statistical analysis}

For demographics and pre-existing comorbidities in non-transplant and transplant patients with NDMM by LOT, Mantel-Haenszel chi-squared tests for categorical variables and t-tests for continuous variables were conducted. Logistic regression analyses were conducted to characterize and compare patients who did not receive a subsequent LOT after LOT1 with those who received LOT2 and beyond. To account for censoring, a sensitivity analysis was conducted in which the occurrence of a subsequent treatment for patients who had follow-up 
data available for at least $6+, 12+$, and $24+$ months was evaluated. For this analysis, cardiovascular disorders (cardiac arrythmia, congestive heart failure, complicated hypertension, and valvular disease) were consolidated into a single variable to reduce the number of covariates in the model. Attrition rates were reported for patients who received transplant and up to five LOTs.

\section{Results}

\section{Patients and baseline characteristics}

This analysis included patient-level data from patients with NDMM who did not receive ASCT (non-transplant, $n=22,062$ ) and who received ASCT (transplant, $n=2763)$. Patient demographics and pre-existing comorbidities by LOT are shown in Table 1 . The median (Q1-Q3) age was $72.0(65.0-79.0)$ years for nontransplant patients and $65.0(57.0-69.0)$ years for transplant patients. Non-transplant patients had a higher mean (SD) baseline score compared with transplant patients (1.5 [1.8] vs. 1.2 [1.7]). Non-transplant patients who received only 1 LOT were significantly older than those who received > 1 LOT (median [Q1-Q3] age, 73.0 [65.0-80.0] years vs. 72.0 [65.0-78.0] years; $p<0.0001)$, and had higher mean CCI scores and higher incidences of all comorbidities except simple hypertension (Table 1). Similarly, transplant patients who received only 1 LOT were older than those who received > 1 LOT (median [Q1-Q3] age, 65.0 [57.0-69.0] years vs. 64.0 [57.0-69.0] years) and had higher mean CCI scores and higher incidences of all comorbidities except congestive heart failure (Table 1).

Of the 2763 transplant-eligible patients, 1682 (60.9\%) received a transplant with frontline induction therapy. Of the transplant patients who received frontline induction therapy, $187(11.1 \%)$ also received consolidation therapy. Patients who received consolidation therapy were younger compared with those who did not receive consolidation (median [Q1-Q3] age, 62.0 [55.0-68.0] years vs. 65.0 [58.0-69.0] years), had lower mean CCI and comparable or lower incidences of selected comorbidities (Table 1).

More non-transplant patients had comorbidities during the 180 days prior to their MM diagnosis compared with transplant patients (cardiac arrhythmia, 19.6\% vs. $10.6 \%$; congestive heart failure, $13.5 \%$ vs. $4.2 \%$; hypertension [complicated], $16.9 \%$ vs. $9.4 \%$; and renal impairment, $24.1 \%$ vs. $17.0 \%$ ) (Table 2 ). When stratified by age, non-transplant patients generally presented with more comorbidities than transplant patients within the same age group. However, the differences were less pronounced in subgroups of patients who were 65-74 and 75-84 years of age, with a higher incidence of some preexisting comorbidities observed among transplant patients (Table 2).
For non-transplant patients, logistic regression analysis showed that several baseline characteristics and comorbidities were associated with receiving further LOT. In the overall population, patients with older age, cardiovascular disorders, pulmonary circulation disorders, and renal impairment were less likely to receive further LOT. For the sensitivity analyses, in which patients who had $6+, 12+$, and $24+$ months of follow-up data were restricted, older age and cardiovascular disorders were associated with higher attrition rates (Table 3). Among transplant-eligible patients, younger age $(<65$ years $)$ was a predictor of subsequent treatment, with patients significantly more likely to receive subsequent therapy at the $12+$ and $24+$ month follow-up. Liver disease was associated with higher attrition rates for the overall population and for patients with $6+, 12+$, and $24+$ months of follow-up data (Table 3).

\section{Frontline treatment regimens}

For non-transplant patients, frontline treatment regimens varied, with Vd (20\%) and lenalidomide/dexamethasone (Rd; 19\%) being the most common (Fig. 1a). The most common induction treatment regimens for transplant patients were bortezomib/lenalidomide/dexamethasone (VRd; 33\%) and other bortezomib-containing regimens (29\%) (Fig. 1b). Among patients who received consolidation therapy (ongoing for $\geq 1$ month after ASCT, and the same regimen as used for induction, or a new regimen which included the induction therapy), the majority received either VRd (41\%) or other bortezomibcontaining regimens (38\%).

\section{Attrition by LOT}

Attrition rates across all LOTs were high for nontransplant patients (range, 43-57\%) and transplant patients (range, 21-37\%); rates of attrition were higher for the non-transplant patients (Table 4). After frontline therapy, $43 \%$ of non-transplant patients and $79 \%$ of transplant patients received a second LOT, and of these, only $55 \%$ and $69 \%$ went on to receiving a third LOT, respectively. Only $8 \%$ of total non-transplant patients and $22 \%$ of total transplant patients received a fifth LOT. The incidence of death was higher at each LOT for nontransplant (19-22\%) vs. transplant patients (3-12\%), with comparable treatment duration (Table 4).

For non-transplant patients, the duration of treatment decreased with each LOT, except for the duration of the second LOT (6.9 months for frontline treatment, 7.5 months for LOT2, and 6.5 months for LOT3) (Fig. 2). For patients who received transplant, treatment duration was relatively constant by LOT; with a mean duration of 6.3 months and 6.1 months for the first two LOTs, respectively (Fig. 2). 


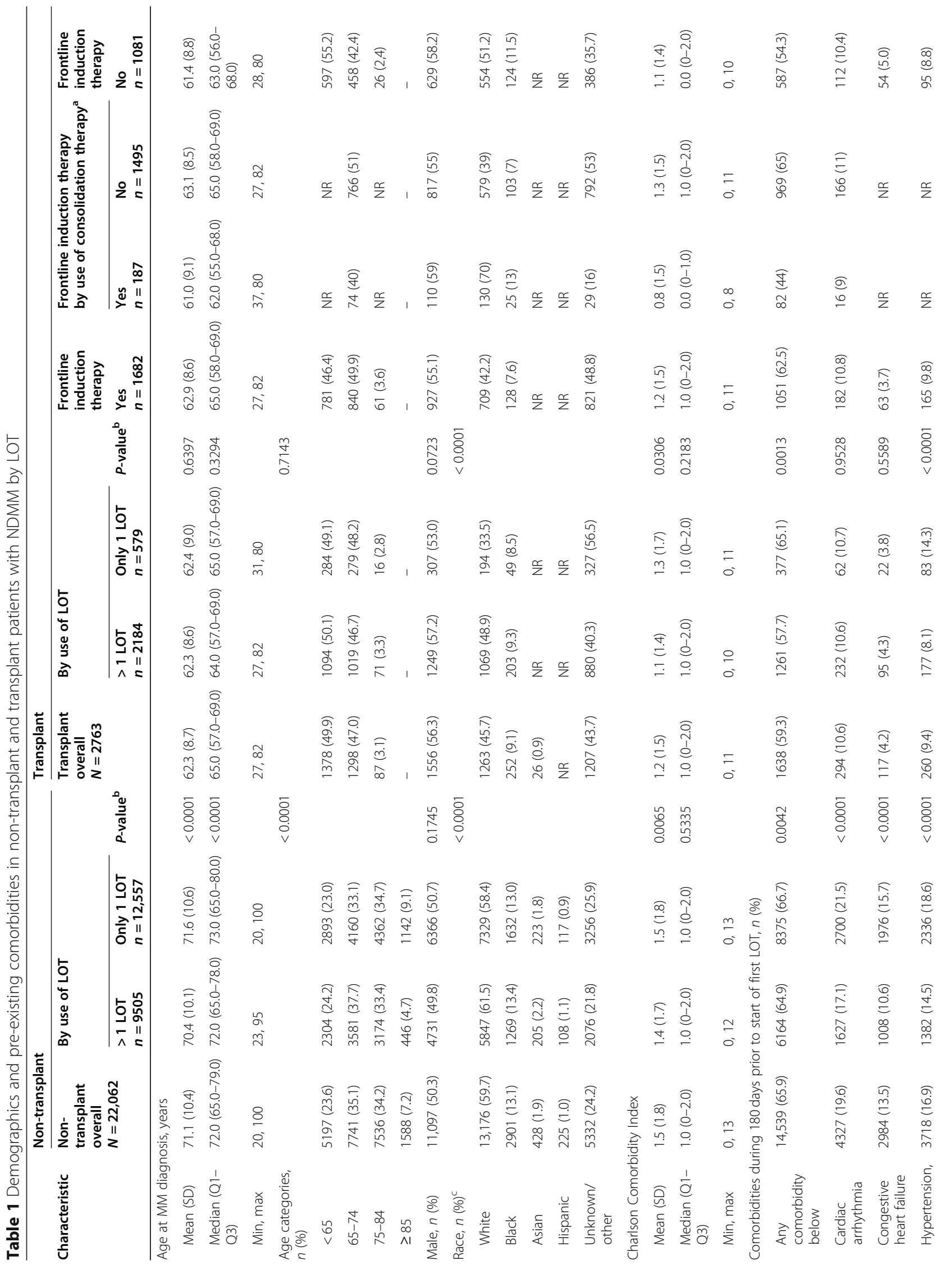




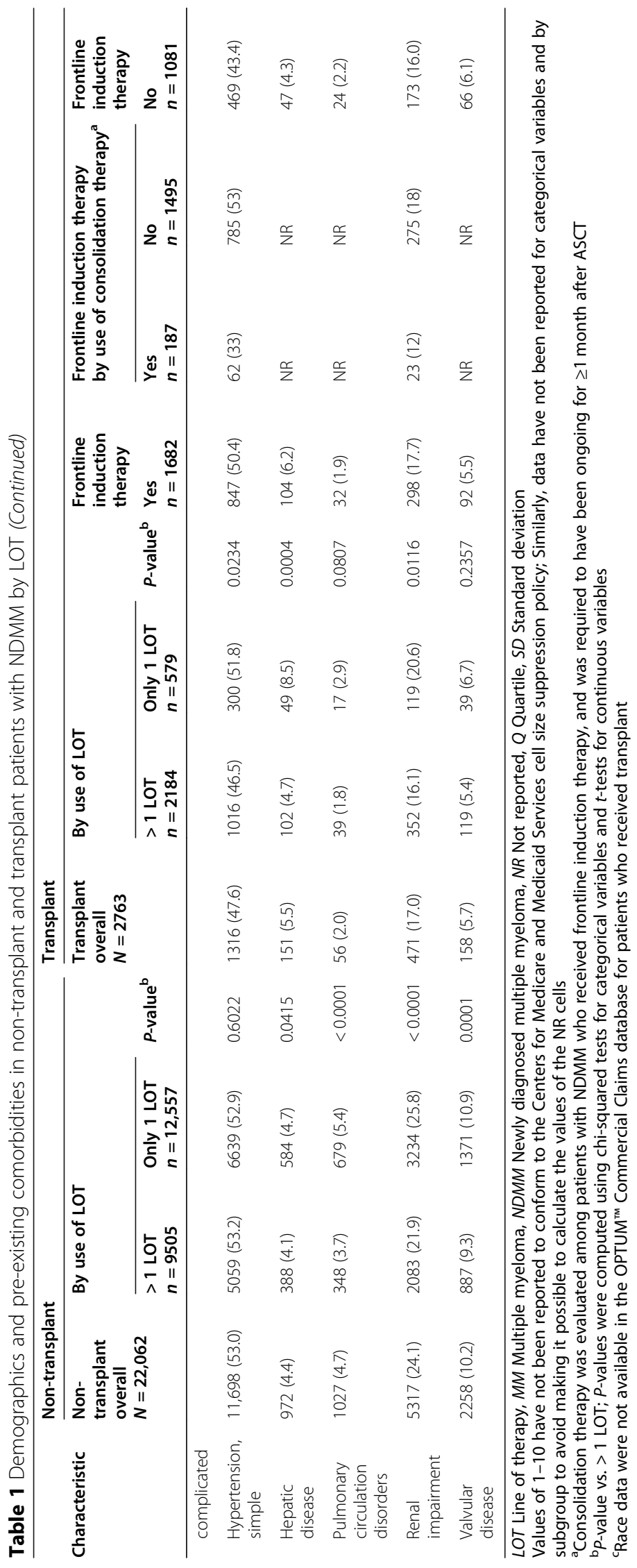




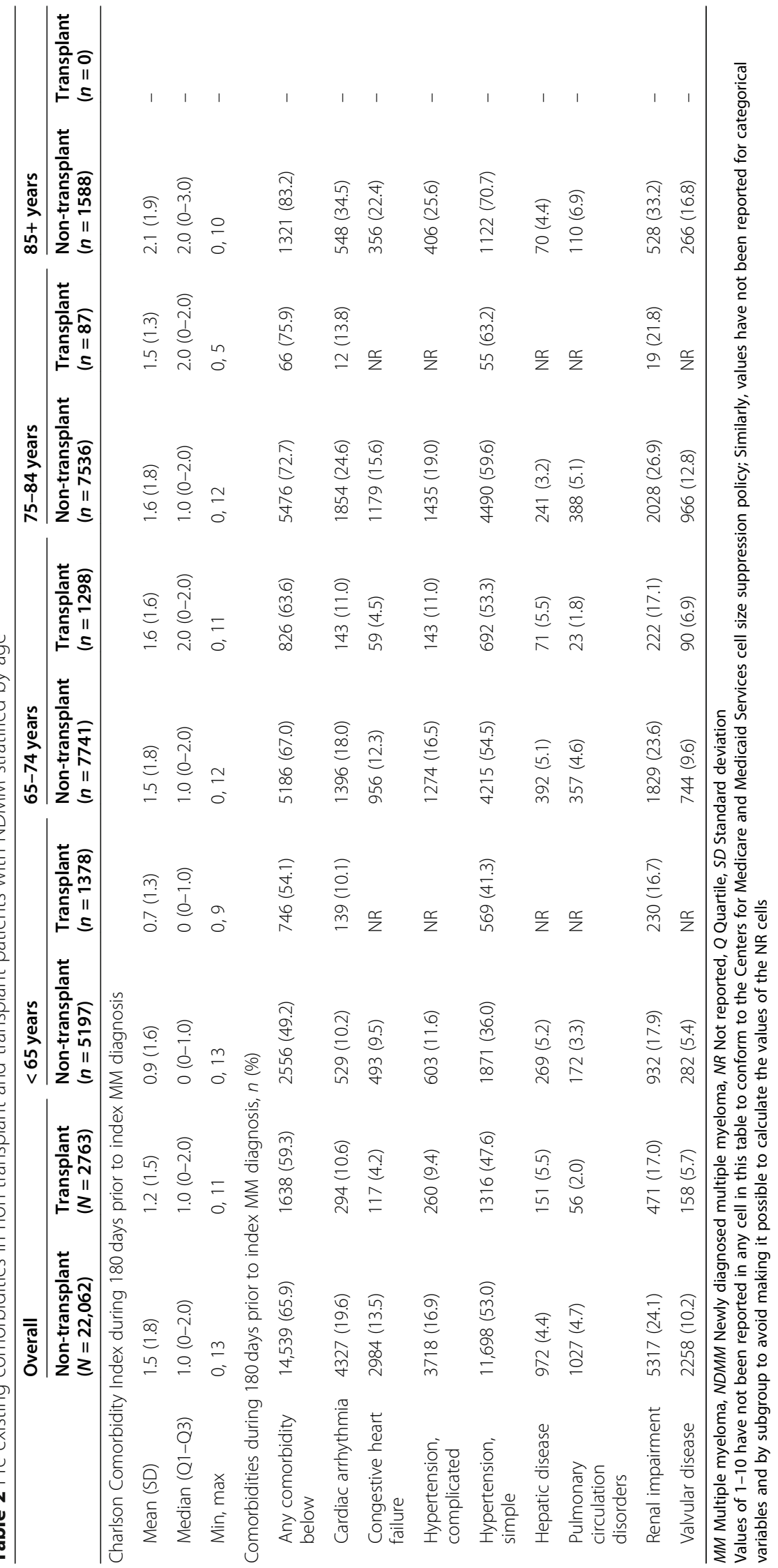




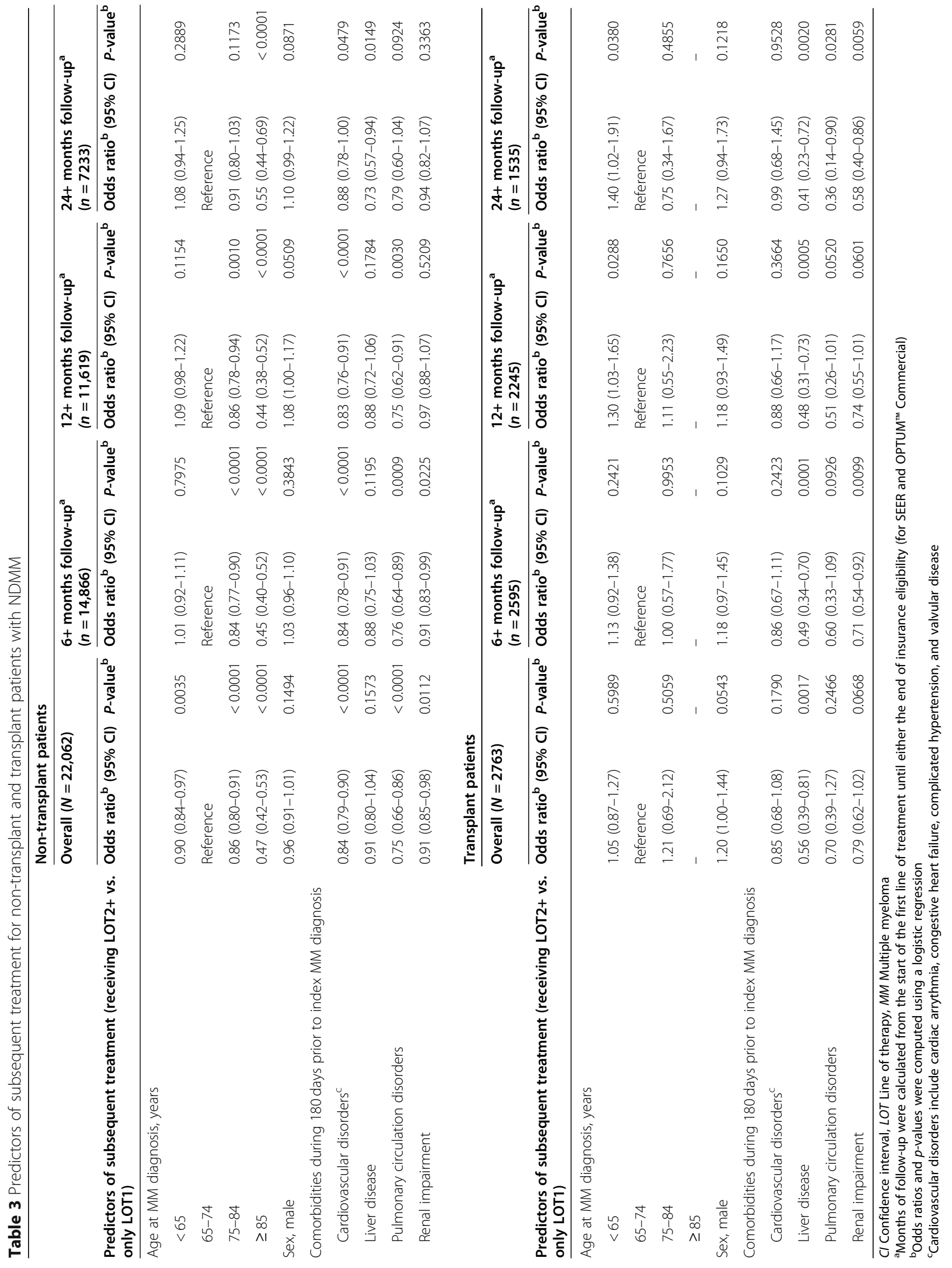


A
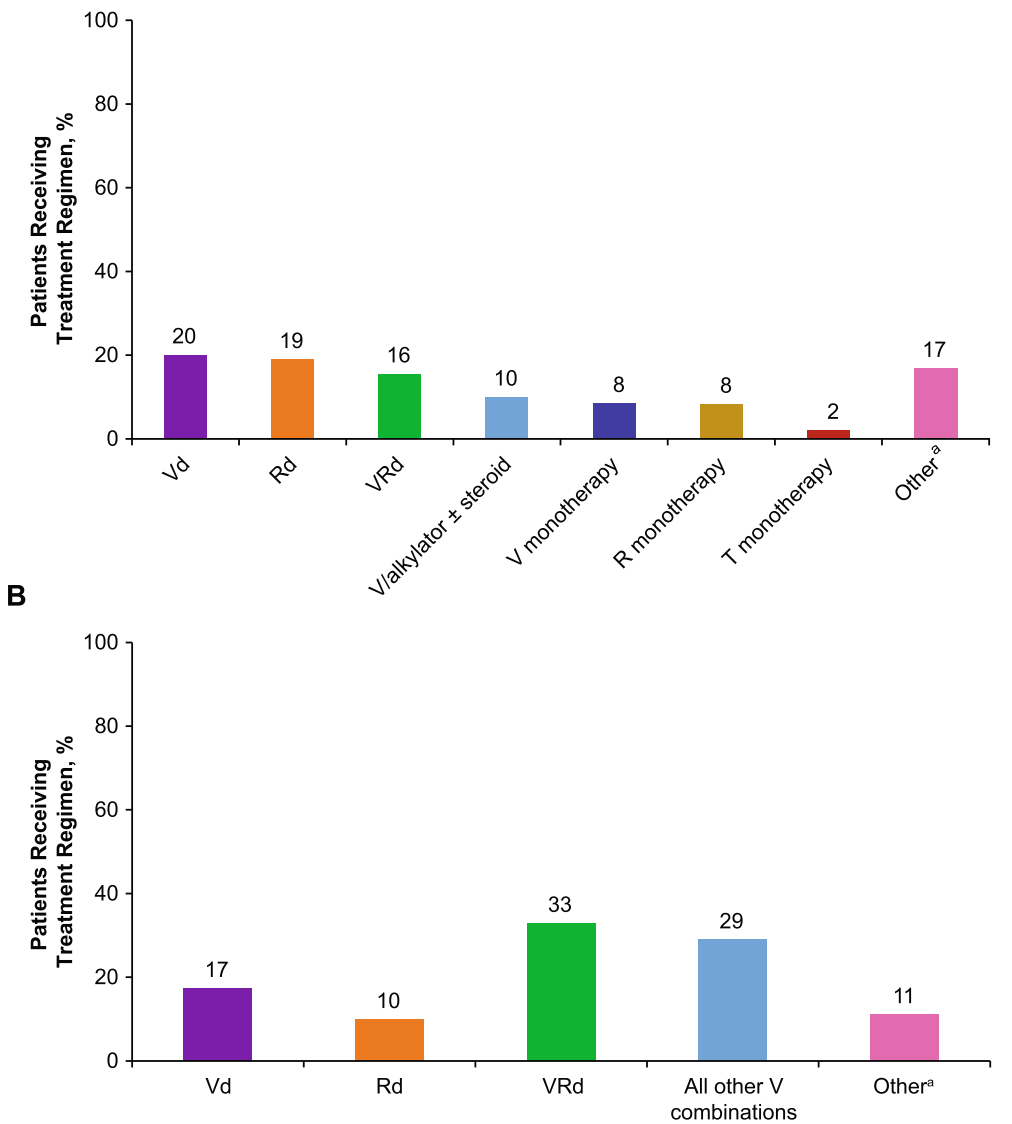

Fig. 1 Frequently used frontline treatment regimens for patients with NDMM (a) who did not receive stem cell transplant (non-transplant) and (b) who received stem cell transplant (transplant). NDMM Newly diagnosed multiple myeloma, Vd Bortezomib/dexamethasone, Rd Lenalidomide/ dexamethasone, VRd Bortezomib/lenalidomide/dexamethasone, V/alkylator Bortezomib/alkylating agent, V Bortezomib, $R$ Lenalidomide, $T$ Thalidomide. ${ }^{\mathrm{a}}$ Other regimens include other combinations of novel agents, such as Td and VR, as well as treatment with cyclophosphamide-containing regimens

Table 4 Attrition rates by LOT

\begin{tabular}{|c|c|c|c|c|c|c|}
\hline LOT & $\begin{array}{l}\text { Frequency, } \\
N\end{array}$ & $\begin{array}{l}\text { Attrition, } \\
\%\end{array}$ & $\begin{array}{l}\text { Deaths, } n \\
\text { (\%) }\end{array}$ & $\begin{array}{l}\text { No subsequent treatment in } \\
\text { follow-up, } n(\%)\end{array}$ & $\begin{array}{l}\text { Subsequent } \\
\text { treatment, } n(\%)\end{array}$ & $\begin{array}{l}\text { Mean } \pm \text { SD treatment duration, } \\
\text { months (median) }\end{array}$ \\
\hline \multicolumn{7}{|c|}{ Non-transplant } \\
\hline 1 & 22,062 & - & $2841(12.9)$ & $9716(44.0)$ & 9505 (43.1) & $6.9 \pm 9.6(3.6)$ \\
\hline 2 & 9505 & 56.9 & $1155(12.2)$ & 3168 (33.3) & $5182(54.5)$ & $7.5 \pm 9.5(4.1)$ \\
\hline 3 & 5182 & 45.5 & $636(12.3)$ & 1575 (30.3) & 2971 (57.3) & $6.5 \pm 8.0(3.7)$ \\
\hline 4 & 2971 & 42.7 & $364(12.3)$ & $901(30.3)$ & 1706 (57.4) & $5.7 \pm 6.6(3.4)$ \\
\hline 5 & 1706 & 42.6 & 209 (12.3) & $508(29.8)$ & $989(58.0)$ & $5.5 \pm 6.4(3.2)$ \\
\hline \multicolumn{7}{|c|}{ Transplant } \\
\hline 1 & 2763 & - & $36(1.3)$ & 543 (19.6) & $2184(79.0)$ & $6.3 \pm 8.0(4.2)$ \\
\hline 2 & 2184 & 21.0 & $60(2.7)$ & $613(28.1)$ & $1511(69.2)$ & $6.1 \pm 9.2(2.7)$ \\
\hline 3 & 1511 & 30.8 & $63(4.2)$ & $494(32.7)$ & $954(63.1)$ & $7.4 \pm 9.8$ (3.6) \\
\hline 4 & 954 & 36.9 & $60(6.3)$ & $276(28.9)$ & $618(64.8)$ & $6.6 \pm 9.4(3.4)$ \\
\hline 5 & 618 & 35.2 & $49(7.9)$ & $180(29.1)$ & 389 (62.9) & $5.6 \pm 6.2(3.3)$ \\
\hline
\end{tabular}




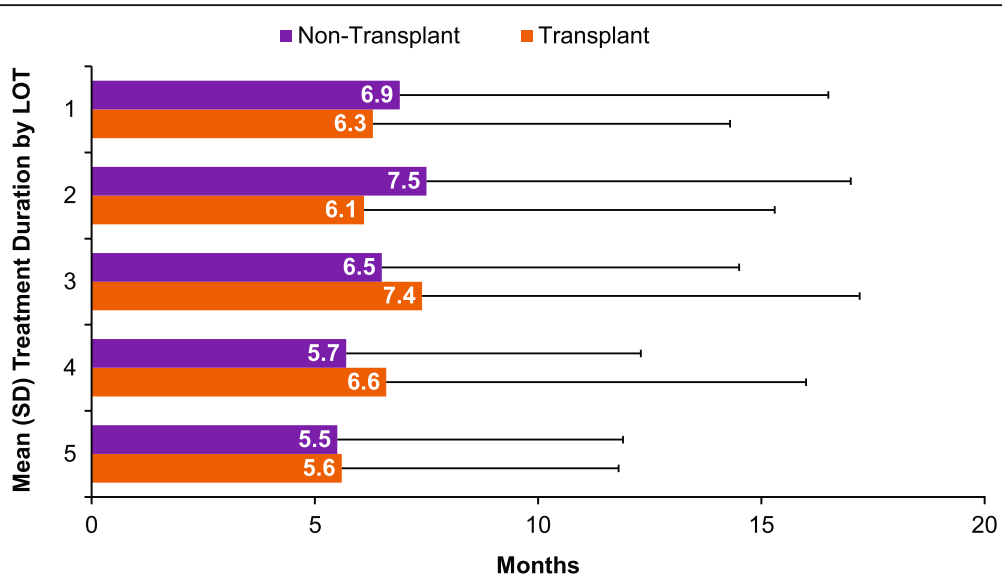

Fig. 2 Mean treatment duration by LOT in patients with NDMM who did not receive stem cell transplant (non-transplant) and those who did receive stem cell transplant (transplant). LOT Line of therapy, SD Standard deviation

\section{Discussion}

This retrospective analysis of real-world data from the United States demonstrates that attrition rates were high (up to 50\% per LOT) and remained steady from the first through the fifth LOT among non-transplant patients. For transplant patients, attrition rates were generally lower, but increased with each successive LOT, ranging from $21-37 \%$. The difference in attrition for nontransplant and transplant patients is not unexpected, given the different baseline characteristics and comorbidities of these two patient populations. For nontransplant patients, older age at diagnosis, cardiovascular disorders, pulmonary circulation disorders, and renal impairment were associated with higher attrition rates beyond the first LOT. For transplant patients, liver disease was associated with higher attrition rates. With longer follow-up, younger transplant patients were more likely to receive a second LOT, and pulmonary circulation disorders and renal impairment were associated with higher attrition rates.

Among non-transplant patients who received frontline therapy, approximately half received a second LOT and as few as $8 \%$ received a fifth LOT. For transplant patients, the proportions in subsequent therapies at each LOT were higher; $79 \%$ received a second LOT and 22\% received a fifth LOT. In similar analyses of European patients with NDMM, 32-61\%, 14-38\%, 15\%, and 1\% received a second, third, fourth, and fifth LOT $[6-8,11]$. These estimates included patients with NDMM from multiple countries and, in some instances, did not differentiate between transplant and non-transplant patients. This analysis of the most recent patient-level data (up to 2018) available from three databases in the United States demonstrates a clear difference in attrition rates among transplant-ineligible and transplant-eligible patients. There was a slight increase in patients receiving subsequent LOTs, although it should be noted that the study included only those patients with NDMM who had received at least one LOT rather than all patients diagnosed with MM. Nevertheless, our analysis is consistent with previous real-world studies [6-8, 11] and demonstrates the occurrence of high attrition rates in early lines of MM therapy. Treatment durations in our study were also generally consistent with other real-world analyses $[6,7,12]$.

$\mathrm{Vd}$ and $\mathrm{Rd}$ were the most common standard-of-care (SoC) frontline treatments for patients who did not receive ASCT; the use of $\mathrm{Rd}$ as frontline therapy in this setting is consistent with current guidelines [13], although the use of triplets is increasing, and use of $\mathrm{Vd}$ is consistent with another real-world analysis reporting that non-transplant patients received $\mathrm{Vd}$ as frontline therapy (13.5\%) [14]. However, these therapies are no longer optimal. For patients who received ASCT, the most common induction therapies were VRd and other bortezomib-containing regimens. These treatment patterns reflect current guidelines recommending that induction therapy include a minimum of bortezomib and dexamethasone [13]. For patients who received frontline induction therapy plus ASCT, the use of consolidation therapy was limited, seen in only $11 \%$ of patients. In our analysis, patients who received consolidation therapy were younger at diagnosis, had lower CCI scores, and had lower rates of cardiac arrhythmia, simple hypertension, pulmonary circulation disorders, and renal impairment. Although this estimate appears low, it is within range of previous real-world analyses (range, 2-22\%) $[11,15]$.

Several limitations should be considered for this retrospective analysis of claims data. Claims data in realworld analyses inherently reflect the individual decisions of physicians as they evaluate and treat patients, which differ from the controlled and standardized methods used in clinical studies. In this real-world dataset, the 
incidence of pre-existing renal insufficiency was higher in non-transplant than transplant patients, which may or may not be attributable to MM. Furthermore, algorithms were used to establish LOTs, the details of which are included in Additional file 1. This may have led to the overestimation of attrition, as it included patients who were lost to follow-up due to a switch in insurance plans, loss of insurance coverage, or end of the study period. Attrition rates may also have been overstated because the database did not include information on patients' disease progression; it was therefore not possible to distinguish between patients who did not experience disease progression and did not receive subsequent treatment and those who had disease progression but did not receive subsequent treatment during the study period. It is possible that some of the MM patients who received frontline therapy may have had smoldering MM. Moreover, this study excluded patients with NDMM who opted to forgo therapy. As such, the data herein should be interpreted in the context of patients who received at least one LOT, rather than the entire MM population. Lastly, comparisons within the same LOT between non-transplant and transplant patients, and comparisons of different LOTs within the transplant group, were not adjusted for exposure, and hence should be interpreted with caution.

\section{Conclusion}

High attrition rates for frontline and subsequent LOTs for MM, coupled with known decreases in overall survival, progression-free survival, and response to treatment with each LOT $[6,8,14,16]$ suggest that the most effective treatment is needed early to provide each patient the best opportunity for durable disease control and improved survival. As newer regimens evolve and are adopted into clinical practice as frontline therapies, further analyses of real-world data should be conducted to confirm whether improved outcomes and decreased attrition rates are associated with the earlier use of these superior therapies in the treatment paradigm.

\section{Supplementary information}

Supplementary information accompanies this paper at https://doi.org/10. 1186/s12885-020-07503-y.

Additional file 1. Business rules to define line of treatment in multiple myeloma [17-19].

\section{Abbreviations}

ASCT: Autologous stem cell transplant; CCl: Charlson Comorbidity Index; LOT: Line of therapy; MM: Multiple myeloma; NDMM: Newly diagnosed multiple myeloma; SOC: Standard of care; Vd: Bortezomib/dexamethasone; VRd: Bortezomib/lenalidomide/dexamethasone

\section{Acknowledgements}

This study used the linked SEER-Medicare database. The interpretation and reporting of these data are the sole responsibility of the authors. The authors acknowledge the efforts of the National Cancer Institute; the Office of Research, Development and Information, CMS; Information Management Services (IMS), Inc.; and the Surveillance, Epidemiology, and End Results (SEER) Program tumor registries in the creation of the SEER-Medicare database.

\section{Authors' contributions}

RF, MM, MS, JH, AL, JU, EMM, and SN contributed to the conception and design, and data analysis and interpretation; MM and RP contributed to the collection and assembly of data, and data analysis and interpretation; and all authors drafted and reviewed the manuscript, approved the final version for submission, and vouch for data accuracy and completeness.

\section{Funding}

This study was funded by Janssen Global Services, LLC. The sponsor and authors were jointly responsible for the conception and design, and data analysis. Editorial support was provided by Eloquent Scientific Solutions, and funded by Janssen Global Services, LLC. All the authors reviewed, revised, and approved the manuscript for submission. The sponsor and authors vouch for data accuracy and completeness.

\section{Availability of data and materials}

The data sharing policy of Janssen Pharmaceutical Companies of Johnson \& Johnson is available at https://www.janssen.com/clinical-trials/transparency. As noted on this site, requests for access to the study data can be submitted through Yale Open Data Access (YODA) Project site at http://yoda.yale.edu.

\section{Ethics approval and consent to participate}

As the databases used contain only retrospective data, and since patients are not identifiable, approval and written informed consent by patients or Institutional Review Board/Independent Ethical Committee approvals are not required.

\section{Consent for publication}

Not applicable.

\section{Competing interests}

Rafael Fonseca served as a consultant for AbbVie, Aduro, Amgen, Bayer, BMS/Celgene, GlaxoSmithKline, Janssen, Juno, Kite, Merck, Novartis,

Oncotracker, Pharmacyclics, and Sanofi; and participated in an advisory board for Adaptive Biotechnologies. Saad Z. Usmani served as a consultant/ advisor for Amgen, Bristol-Myers Squibb, Celgene, Janssen, Merck, SkylineDx, and Takeda; participated in a Speakers Bureau for Amgen, Celgene, Janssen, Sanofi, and Takeda; and received research grants from Amgen, Array Biopharma, Bristol-Myers Squibb, Celgene, Janssen, Merck, Pharmacyclics, Sanofi, and Takeda. Maneesha Mehra, Mary Slavcev, Jianming He, Sarah Cote, Annette Lam, Jon Ukropec, and Sandhya Nair are employees of Janssen. Eric M. Maiese was an employee of Janssen at the time the study was conducted. Ravi Potluri is an employee of SmartAnalyst Inc. Peter M. Voorhees received research funding from Amgen, Celgene, GlaxoSmithKline, Janssen, and Takeda; and served as a consultant/advisor for Adaptive Biotechnologies, Bristol-Myers Squibb, Celgene, Janssen, Novartis, Oncopeptides, Takeda, and TeneBio.

\section{Author details}

${ }^{1}$ Division of Hematology and Oncology, Mayo Clinic, 13400 E. Shea Blvd., MCCRB 3-001, Phoenix, AZ 85259, USA. '²evine Cancer Institute/Atrium Health, Charlotte, NC, USA. ${ }^{3}$ Janssen Global Services, LLC, Raritan, NJ, USA. ${ }^{4}$ Janssen Global Medical Affairs, Horsham, PA, USA. ${ }^{5}$ Janssen Scientific Affairs, Horsham, PA, USA. ${ }^{6}$ Janssen Pharmaceutica NV, Beerse, Belgium.

${ }^{7}$ SmartAnalyst Inc., New York, NY, USA.

Received: 10 May 2020 Accepted: 6 October 2020

Published online: 10 November 2020

\section{References}

1. SEER Cancer Stat Facts: Myeloma. Bethesda: National Cancer Institute. https://seer.cancer.gov/statfacts/html/mulmy.html. Accessed 24 Feb 2020. 
2. Mikhael J, Ismaila N, Cheung MC, Costello C, Dhodapkar MV, Kumar S, et al. Treatment of multiple myeloma: ASCO and CCO joint clinical practice guideline. J Clin Oncol. 2019;37(14):1228-63.

3. Moreau P, San Miguel J, Sonneveld P, Mateos MV, Zamagni E, Avet-Loiseau $\mathrm{H}$, et al. Multiple myeloma: ESMO Clinical Practice Guidelines for diagnosis, treatment and follow-up. Ann Oncol. 2017;28(suppl_4):iv52-61.

4. Attal M, Harousseau JL, Stoppa AM, Sotto JJ, Fuzibet JG, Rossi JF, et al. A prospective, randomized trial of autologous bone marrow transplantation and chemotherapy in multiple myeloma. N Engl J Med. 1996;335(2):91-7.

5. Child JA, Morgan GJ, Davies FE, Owen RG, Bell SE, Hawkins K, et al. Highdose chemotherapy with hematopoietic stem-cell rescue for multiple myeloma. N Engl J Med. 2003;348(19):1875-83.

6. Yong K, Delforge M, Driessen C, Fink L, Flinois A, Gonzalez-McQuire S, et al. Multiple myeloma: patient outcomes in real-world practice. $\mathrm{Br} J$ Haematol. 2016;175(2):252-64.

7. MacEwan JP, Batt K, Yin W, Peneva D, Sison S, Vine S, et al. Economic burden of multiple myeloma among patients in successive lines of therapy in the United States. Leuk Lymphoma. 2018;59(4):941-9.

8. Antunes L, Rocha-Goncalves F, Chacim S, Lefevre C, Pereira M, Pereira S, et al. Real-world treatment patterns, resource use and cost burden of multiple myeloma in Portugal. Eur J Cancer Care (Engl). 2019;28:e13026.

9. Despiégel N, Touboul C, Flinois A, Saba G, Suzan F, Gonzalez-McQuire S, et al. Health-related quality of life of patients with multiple myeloma treated in routine clinical practice in France. Clin Lymphoma Myeloma Leuk. 2019;19(1):e13-28.

10. Quan H, Li B, Couris CM, Fushimi K, Graham P. Hider P, et al. Updating and validating the Charlson comorbidity index and score for risk adjustment in hospital discharge abstracts using data from 6 countries. Am J Epidemiol. 2011;173(6):676-82.

11. Raab MS, Cavo M, Delforge M, Driessen C, Fink L, Flinois A, et al. Multiple myeloma: practice patterns across Europe. Br J Haematol. 2016;175(1):66-76.

12. Gonzalez-McQuire S, Yong K, Leleu H, Mennini FS, Flinois A, Gazzola C, et al. Healthcare resource utilization among patients with relapsed multiple myeloma in the UK, France, and Italy. J Med Econ. 2018;21(5):450-67.

13. National Comprehensive Cancer Network. NCCN Clinical Practice Guidelines in Oncology. Multiple Myeloma Version 2. 2019. https:/www.nccn.org/ professionals/physician_gls/pdf/myeloma.pdf. Accessed 24 Feb 2020.

14. Mohty M, Terpos E, Mateos MV, Cavo M, Lejniece S, Beksac M, et al. Multiple myeloma treatment in real-world clinical practice: results of a prospective, multinational, noninterventional study. Clin Lymphoma Myeloma Leuk. 2018;18(10):e401-19.

15. Moehler TM, Merz M, Kellermann L, Goldschmidt H, Knauf W. Diagnostic and therapeutic approaches to multiple myeloma patients: 'real-world' data from representative multicentre treatment surveys in Germany between 2008 and 2011. Oncol Lett. 2016;12(6):5043-51.

16. Hajek R, Jarkovsky J, Maisnar V, Pour L, Spicka I, Minarik J, et al. Real-world outcomes of multiple myeloma: retrospective analysis of the Czech registry of monoclonal gammopathies. Clin Lymphoma Myeloma Leuk. 2018;18(6): e219-40.

17. Usmani S, Ahmadi T, Ng Y, Lam A, Desai A, Potluri R, et al. Analysis of realworld data on overall survival in multiple myeloma patients with $>/=3$ prior lines of therapy including a proteasome inhibitor (PI) and an immunomodulatory drug (IMiD), or double refractory to a PI and an IMiD. Oncologist. 2016;21(11):1355-61.

18. Flaig TW, Potluri RC, Ng Y, Todd MB, Mehra M. Treatment evolution for metastatic castration-resistant prostate cancer with recent introduction of novel agents: retrospective analysis of real-world data. Cancer Med. 2016; 5(2):182-91

19. Kubitz N, Mehra M, Potluri RC, Garg N, Cossrow N. Characterization of treatment resistant depression episodes in a cohort of patients from a US commercial claims database. PLoS One. 2013;8(10):e76882.

\section{Publisher's Note}

Springer Nature remains neutral with regard to jurisdictional claims in published maps and institutional affiliations.

\section{Ready to submit your research? Choose BMC and benefit from:}

- fast, convenient online submission

- thorough peer review by experienced researchers in your field

- rapid publication on acceptance

- support for research data, including large and complex data types

- gold Open Access which fosters wider collaboration and increased citations

- maximum visibility for your research: over $100 \mathrm{M}$ website views per year

At BMC, research is always in progress.

Learn more biomedcentral.com/submissions 